Applied Composite Materials

April 2018, Volume 25, Issue 2, Pages 299-308

http://dx.doi.org/10.1007/s10443-017-9619-3

http://archimer.ifremer.fr/doc/00392/50385/

(C) Springer Science+Business Media B.V. 2017

\title{
Evaluation of Basalt Fibre Composites for Marine Applications
}

\author{
Davies Peter ${ }^{1,{ }^{*}}$, Verbouwe W. ${ }^{2}$ \\ 1 IFREMER, Centre BretagneMarine Structures LaboratoryPlouzanéFrance \\ 2 BASALTEX NV, WevelgemBelgium \\ *Peter Davies, email address : peter.davies@ifremer.fr
}

\begin{abstract}
:
Basalt fibres offer potential for use in marine structures, but few data exist to evaluate the influence of seawater immersion on their mechanical behaviour. This paper provides the results from a study in which basalt fibre reinforced epoxy composites were aged in natural seawater at different temperatures. Tests were performed under quasi-static and cyclic loading, first in the as-received state then after saturation in natural seawater. Results are compared to those for an E-glass reinforced composite with the same epoxy matrix. They indicate similar mechanical performance for both materials after seawater saturation.
\end{abstract}

Keywords : Seawater, Aging, Fatigue, Basalt fibre, Epoxy, Unidirectional, Flexure 


\section{Introduction}

The marine composite industry is dominated by glass fibre reinforced materials. These have been in use for over 50 years, and provide excellent properties at reasonable cost. For high performance applications carbon and occasionally aramid fibres are used, but there has been no challenge to glass fibres since their introduction. In recent years however, there has been some interest in basalt fibres for composite structures [1]. Basalt is a natural material found in volcanic rocks; basalt fibres were developed in Russia in the 1950's and are now commercially available. Various reasons have been given for adopting them as a composite reinforcement in place of glass, including lower energy required to manufacture them [2], improved tensile properties, improved corrosion resistance compared to E-glass [3] and improved temperature stability [4]. All these advantages are open to discussion, but if basalt fibre composites are to be used in marine structures it is essential to know how they respond to sea water aging.

Few data are available at present. Early work by Ramachandran et al [5] indicated that basalt fibre has excellent resistance to alkaline attack, but poor resistance to acids. More recently Elshafie and Whittleston [6] described results from an extensive series of tests on basalt and glass fibres under different environmental conditions (acid, alkaline and at different temperatures). They concluded that basalt fibres were more capable of retaining their strength than glass fibres when immersed in different alkaline and acid environments. Liu et al [7] reported results from a study of glass and basalt fabric reinforced epoxy and vinylester composites. These were produced by hand lay-up so the fibre contents were quite low, around $38 \%$ by volume. Tensile tests were performed after 240 days aging in seawater at room temperature and properties did not change significantly but interlaminar shear strength dropped. This was attributed to degradation of the fibre/matrix interface and it was concluded (in 2006) that the interfacial region of basalt reinforced composites required modification prior to use in long-term applications involving exposure to water. Elgabbas et al [8] also studied basalt fibre reinforced composites for concrete reinforcement and aged samples for up to $3000 \mathrm{~h}$ at $60^{\circ} \mathrm{C}$ in alkaline solution. They noted poor alkaline resistance and interface issues. Wei et al [9] aged woven basalt and glass fibre reinforced epoxy composites in seawater for up to 90 days at $25^{\circ} \mathrm{C}$ and measured 
residual tensile and flexural properties. These authors found very similar losses in strength properties for both materials, around $30 \%$ after 90 days, under these less severe conditions. Wu et al presented tensile test results for unidirectional basalt immersed for 55 days at $60^{\circ} \mathrm{C}$ in various liquids [10], and concluded that basalt fibers possess relatively strong resistance to water and salt corrosion, moderate resistance to acid corrosion and severe degradation in an alkaline solution. Subramanian \& Shu describe a range of silane coupling treatments which can significantly improve basalt fibre interface properties [11]. Both acid and base surface treatments were applied to basalt fibres by Manikandan et al [12], who showed that the ferric oxide in basalt fibres reacts with sulphuric acid and can improve the interface between these fibres and polyester resin.

There is clearly some variability in results from these published chemical resistance studies, which is hardly surprising as they depend not only on the basalt fibres but also on details of the matrix and interface properties and on the test conditions.

Some fatigue data have been published: Wu et al [13] presented tension fatigue S-N results for quasiunidirectional basalt reinforced epoxy as part of a study of several composites with different fibres, and concluded that fatigue behavior was similar to that of conventional glass composites. They indicated values for normalized loss of applied stress per decade as around $7 \%$ for basalt fibre composites and around $6 \%$ for glass. Colombo et al [14] also showed tensile fatigue plots, for epoxy and vinylester quasi-isotropic composites using Basaltex ${ }^{\mathrm{TM}}$ biaxial fabrics. Their results indicated a slope of the normalized stress-log cycles to fail plot (with applied stress divided by mean static break stress) of around $-7.7 \% /$ decade for the epoxy and $-9.6 \% /$ decade for the vinylester.

Zhao et al [15] produced some high cycle fatigue data (up to $10^{7}$ cycles) on impregnated basalt bundles in a study to evaluate these materials for bridge cable applications, and identified loading conditions under which fibre failure dominated at high loads, and others at lower loads at which matrix and interface damage controlled failure. Finally, a very recent paper by Shi et al describes tensile fatigue tests on pultruded basalt/epoxy tendons (fibre volume content $70 \%$ ) before and after immersion for up to 63 days in salt solution at up to $55^{\circ} \mathrm{C}$ [16]. The noted a shift to lower lifetimes as 
aging time and temperature increased, but the slope of the S-N plots remained quite constant, with around 4 to $5 \%$ drops in normalized stress per decade.

In conclusion, there are wet aging results and some fatigue data available. However, the quality of the samples tested is not always specified, and very few authors have reported results for fatigue after SW aging. The aim of the present paper is to present results a comparison study on carefully prepared samples of the same matrix epoxy reinforced by glass and basalt fibres, in order to quantify the retention of fatigue strength after long term sea water exposure. These data are essential if basalt fibre composites are to be used in critical marine applications.

\section{Materials and Methods}

The samples supplied for the tests described here were provided by Basaltex, Belgium. Table 1 provides sample details.

Table 1. Constituents of samples tested

Materials were supplied in the form of one unidirectional $500 \times 500 \mathrm{~mm}^{2}$ panel of each, around $3 \mathrm{~mm}$ thick, manufactured by the SLC-lab of Sirris using vacuum infusion. The panels were post-cured at 80 ${ }^{\circ} \mathrm{C}\left(2\right.$ hours at $50^{\circ} \mathrm{C}$ then 30 minutes heating up to $80{ }^{\circ} \mathrm{C}$ and 2.5 hours at $80^{\circ} \mathrm{C}$ ). The glass transition temperature (Tg) values for both materials determined by DSC were in the range 75 to $80^{\circ} \mathrm{C}$. Fibre content and composite density were measured by TGA (thermo-gravimetric analysis in a nitrogen atmosphere to avoid oxidation) and helium gas pycnometry. Table 2 shows values from TGA and pycnometer analyses. The density of these basalt fibres is around 2.67 , slightly higher than that of Eglass (2.60).

Table 2. Fibre contents and density values

Samples were cut from panels using a diamond tipped saw. The following tests were performed: 
- Immersion in natural continuously renewed seawater tanks at 4, 25, 40 and $60^{\circ} \mathrm{C}$ (to evaluate diffusion kinetics for both materials. 3 coupons of each material $(50 \times 50) \mathrm{mm}^{2}$ were immersed at each temperature,

- ILSS (interlaminar shear strength), according to ASTM D2344, under displacement control at $5 \mathrm{~mm} / \mathrm{min} ., 5$ specimens per condition

- Quasi-static 4-point flexure, 3 specimens per condition, $100 \mathrm{~mm}$ between supports, $50 \mathrm{~mm}$ between loading points, under displacement control at $2 \mathrm{~mm} /$ minute, and

- Cyclic 4-point flexure (sinusoidal load control, $2 \mathrm{~Hz}, \mathrm{R}=0.1$ ) with the same geometry as the quasi-static tests.

All the mechanical tests were performed on both unaged specimens and on specimens which had been previously saturated in natural seawater at $40^{\circ} \mathrm{C}$. For the static tests, specimens were kept in seawater at room temperature until just before testing, which was performed in air on an Instron ${ }^{\circledR} 556610 \mathrm{kN}$ test machine, in a temperature $\left(21^{\circ} \mathrm{C}\right)$ and humidity $(50 \% \mathrm{RH})$ controlled laboratory.

The cyclic tests were performed on two Zwick ${ }^{\circledR} 25 \mathrm{kN}$ capacity test frames equipped with temperature controlled, continuously renewed natural seawater baths at $25^{\circ} \mathrm{C}$ which have been described previously [17]. Specimens were removed from the aging tank at $40^{\circ} \mathrm{C}$, weighed, then placed in the seawater baths of the fatigue machines at $25^{\circ} \mathrm{C}$ until testing.

\section{Results}

The results from immersion in seawater will be presented first, then quasi-static mechanical properties, and finally fatigue behaviour.

\section{Seawater aging}

Coupons were immersed at four seawater aging temperatures: 4, 25, 40 and $60^{\circ} \mathrm{C}$. Figure 1 shows an example of the weight gain plots after an immersion period of 200 days for each temperature and each 
composite. Mean values from the 3 coupons at each temperature were then used to determine the diffusion coefficients and saturation weight gains, Table 3. In order to be able to estimate the diffusion coefficients for temperatures at which samples did not reach saturation $\left(4,25^{\circ} \mathrm{C}\right)$ the mass at saturation was assumed to be the same as for the higher temperatures.

Table 3. Mean diffusion coefficients and weight gains at saturation

Figure 1. Weight gain plots for 200 days' immersion at 4 temperatures, a) Glass/epoxy, b)

Basalt/epoxy

Both the diffusion coefficients and the weight gains at saturation are similar for the two materials, suggesting that it is the epoxy resin rather than the fibres or fibre/matrix interfaces which is controlling diffusion. This also suggests that defect levels are similar for both materials.

\section{Quasi-static mechanical properties}

Table 4 shows ILSS values before and after aging.

Table 4. ILSS results, mean (standard deviation) before and after aging

The values are very similar for both materials before aging, suggesting that the interface quality of the unaged samples is similar. The effect of seawater is to reduce the ILSS values by about $10 \mathrm{MPa}$ for both composites. Table 5 shows the flexural modulus and strength values before and after saturation with seawater. The stiffness values are similar for both materials and drop slightly when they are saturated with water. However, the initial strength before aging is significantly higher for the basalt composite. The strength values after seawater saturation are similar for both materials. The flexural failure mode was upper face compression and delamination.

Table 5. Flexural properties, mean (standard deviation) before and after aging 


\section{Cyclic flexural behaviour}

Two machines of the type shown in Figure 1 were used for the cyclic flexural tests in seawater. Figure 2 shows the S-N plots for the two materials in the as-received state. Figures $3 a$ and $3 b$ show the influence of aging on the cyclic behavior of both materials.

Figure 2. S-N plots unaged materials

Figure 3. S-N plots for unaged and aged materials, a) Glass/epoxy, b) Basalt/epoxy

The failure modes are compression and delamination in all cases, no tensile failures were observed. Figure 4 shows the aged specimens after cyclic flexural failure.

Figure 4. Flexural fatigue specimens showing failures on upper (compression) side of specimens, basalt/epoxy on left, glass/epoxy on right.

An electron microscope examination of fracture surfaces suggested that while this epoxy resin appears to remain quite ductile after aging, the failure mechanism in the basalt composite involves the fibre/matrix interface, Figure 5. This suggests that there is further room for improvement in the fatigue behaviour of these materials.

Figure 5. Fracture surfaces of aged basalt/epoxy composite after fatigue failure.

\section{Summary of influence of seawater aging}

The main difference observed between the basalt and glass fibre reinforced composites is a change in the slope of the flexural fatigue plot of the former after aging. However, it is interesting to note that if 
the applied stress values are normalized by the quasi-static flexural strengths (unaged and aged) then the plots superpose quite closely, suggesting that there is not an additional change in failure mechanism due to cyclic loading, Figure 6.

Figure 6. Normalized fatigue plots for basalt/epoxy.

If we then plot the normalized results for the two materials on the same plot we see that for this set of loading conditions the fatigue performance of both materials is very similar and can be described quite well by a single slope of the semi-log plot, Figure 7. This suggests that the influence of seawater is the same in static and in cyclic loading.

Figure 7. All fatigue data, before and after aging, normalized by quasi-static flexural strength values.

The linear behaviour of these materials suggests that a simple slope parameter "B" might be determined, to enable results to be compared. A semi-log expression law can be applied:

Maximum applied stress $\sigma /$ Static break strength $\sigma_{\mathrm{f}}=-\mathrm{B}\left(\log \mathrm{N}_{\mathrm{f}}\right)$

The value of $\mathrm{B}$ is determined by linear regression. Various expressions of this type have been proposed, since the early work of Mandell [18], who suggested that the controlling mechanism in GRP fatigue is the gradual deterioration of load-bearing fibres. Many other more sophisticated damage models have been developed since that early work, various reviews are available [19-22], but for qualitative purposes this simple model can be used to compare these slope values with published results, Table 6.

Table 6. Comparison with values for fatigue slopes obtained on other composite systems using the same four point flexure test fixture in sea water. .

The influence of fatigue on basalt/epoxy composites appears to be similar to that measured for other glass reinforced composites tested under similar conditions. 


\section{Conclusions}

This paper summarizes the influence of seawater aging on the properties of basalt/epoxy composites.

The results show that after saturation glass and basalt /epoxy composites pick up similar amounts of water (around $1.5 \%$ by weight).

The drop in interlaminar shear properties after saturation in seawater is similar for both composites, around $20 \%$.

A larger drop in flexural strength after saturation is noted for the basalt composite. However, as this value was higher initially than that of the glass composite the absolute strength values after aging are similar for both materials.

The same is true of the normalized cyclic test data, which appear quite similar for both materials before and after aging. These results suggest that the long term response of these basalt/epoxy composites in a marine environment is similar to that of E-glass/epoxy. Benefits due to higher initial properties are offset by a higher sensitivity to seawater. However, it should be noted that the glass quasi-unidirectional fabric has a higher proportion of $90^{\circ}$ fibers compared to the basalt fabric, leading to slower infusion for the basalt composites. This might result in lower fiber matrix wetting, and hence lower fiber/matrix interface properties. There may be scope for further improvement through optimization in basalt reinforcement architecture. 


\section{REFERENCES}

[1] Fiore V, Scalici T, Di Bella G, Valenza A, A review on basalt fibre and its composites, Composites Part B, 74 (2015) 74-94

[2] Sim J, Park C, Moon DY. Characteristics of basalt fibre as a strengthening material for concrete structures. Compos Part B (2005), 36, 504-12

[3] Nasir V, Karimipour H, Taheri-Behrooz F, Shokrieh MM. Corrosion behavior and crack formation mechanism of basalt fibre in sulphuric acid. Corrosion Sci (2012) 64,1-7.

[4] Hao LC, Yu WD. Evaluation of thermal protective performance of basalt fibre non-woven fabrics. J Therm Anal Calorim (2010), 100, 551-5.

[5] Ramachandran BE, Velpari V and Balasubramanian N, Chemical durability studies on basalt fibres. J Mater Sci, (1981) 16: 3393-3397.

[6] Elshafie S, Whittleston G, Evaluating the Efficiency of Basalt and Glass Fibres on Resisting the Alkaline, Acid, and Thermal Environments, American Journal of Materials Science 2016, 6(1): 19-34

[7] Wei B, Cao H and Song S. Degradation of basalt fibre and glass fibre/epoxy resin composites in seawater, Corrosion Sci (2011) 53: 426-431.

[8] Liu Q, Shaw MT, Parnas RS, McDonnell M, Investigation of Basalt Fiber Composite Aging Behavior for Applications in Transportation, Polymer Composites, (2006), P75-483

[9] Elgabbas F, Ahmed EA, Benmokrane B, Physical and mechanical characteristics of new basaltFRP bars for reinforcing concrete structures, Construction and Building Materials, 95, (2015), 623-635

[10] Wei B, Cao H, Song S, Degradation of basalt fibre and glass fibre/epoxy resin composites in seawater, Corrosion Science 53 (2011) 426-431

[11] Subramanian RV, Shu KH, Silane Coupling Agents for Basalt Fiber Reinforced Polymer Composites, Chapter in Molecular Characterization of Composite Interfaces, Edited by H. Ishida, G. Kumar, Springer, (1985), pp 205-236

[12] Manikandan V, Winowlin Jappes JT, Suresh Kumar SM, Amuthakkannan P, Investigation of the effect of surface modifications on the mechanical properties of basalt fibre reinforced polymer composites, Composites: Part B 43 (2012) 812-818

[13] Wu Z, Wanga X, Iwashita K, Sasaki T, Hamaguchi Y, Tensile fatigue behaviour of FRP and hybrid FRP sheets, Composites: Part B 41 (2010) 396-402

[14] Colombo C, Vergani L, Burman M, Static and fatigue characterisation of new basalt fibre reinforced composites, Composite Structures, 94, 3, (2012), 1165-1174

[15] Zhao X, Wang X, Wu Z, Zhu Z, Fatigue behavior and failure mechanism of basalt FRP composites under long-term cyclic loads, Int. Journal of Fatigue, 88, (2016), 58-67

[16] Shi J, Wang Z, Wu Z, Zhu Z, Fatigue behavior of basalt fiber-reinforced polymer tendons under a marine environment, Construction and Building Materials 137 (2017) 46-54 
[17] Davies P, Germain G, Gaurier B, Boisseau A, Perreux D, Evaluation of the durability of composite tidal turbine blades, Royal Society Philosophical Transactions A, February 2013 vol. 371

[18] Mandell JF, Fatigue behavior of fibre-resin composites in "Developments in Reinforced Plastics 2, ed. G. Pritchard, 1982, Applied Science Publishers, 67-108.

[19] Beaumont PWR, Physical modeling of damage development in structural composite materials under stress, Chapter 13 in Fatigue in Composites, ed B. Harris, CRC, 2003, 365-412.

[20] Van Paepegem W, Fatigue models for woven textile composite laminates, in Fatigue of textile composites, ed. Edited by:V Carvelli and S V Lomov, 2015, Pages 295-325, Woodhead Publishers.

[21] Boisseau A, Davies P, Thiebaud F, Fatigue Behaviour of Glass Fibre Reinforced Composites for Ocean Energy Conversion Systems, Applied Composite Materials, Vol 20, issue 2 pp145-155, 2013

[22] IFREMER internal test results on unidirectional carbon fibre /M9.6 epoxy composites, October 2010. 


\begin{tabular}{|c|c|c|}
\hline Material & Fibres & Matrix resin \\
\hline Basalt/epoxy & - BASALTEX - BAS UNI 350 & Epoxy \\
& $-0^{\circ} 357 \mathrm{~g} / \mathrm{m}^{2}$ & Araldite $1564 \mathrm{LY} /$ Aradur 3687 \\
& $-90^{\circ} 50 \mathrm{~g} / \mathrm{m}^{2}$ & \\
& - Stitching $9 \mathrm{~g} / \mathrm{m}^{2}$ & Epoxy \\
\hline Glass/epoxy & - E-glass quasi-unidirectional & Araldite $1564 \mathrm{LY} /$ Aradur 3687 \\
& $-0^{\circ} 300 \mathrm{~g} / \mathrm{m}^{2}$ & \\
& $-90^{\circ} 60 \mathrm{~g} / \mathrm{m}^{2}$ & \\
& - Stitching $13 \mathrm{~g} / \mathrm{m}^{2}$ & \\
\hline
\end{tabular}

Table 1. Constituents of samples tested

\begin{tabular}{|l|c|c|c|}
\hline Material & Density & $\begin{array}{c}\text { TGA \% fibres by } \\
\text { weight }\end{array}$ & $\begin{array}{c}\text { Fibre volume } \\
\text { content }\end{array}$ \\
\hline Basalt/epoxy & 1.788 & 66.5 & $44 \%$ \\
\hline Glass/epoxy & 1.784 & 63.8 & $44 \%$ \\
\hline
\end{tabular}

Table 2. Fibre contents and density values

\begin{tabular}{|c|c|c|c|c|}
\hline $\mathrm{m}^{2} / \mathrm{s} \mathrm{x} 10^{-12}$ & $4^{\circ} \mathrm{C}$ & $25^{\circ} \mathrm{C}$ & $40^{\circ} \mathrm{C}$ & $60^{\circ} \mathrm{C}$ \\
\hline \multirow{2}{*}{ Basalt/epoxy } & $2.4(0.3)$ & $7.0(0.8)$ & $19(2)$ & $79(5)$ \\
& - & - & $1.5 \%$ & $1.5 \%$ \\
\hline \multirow{2}{*}{ Glass/epoxy } & $1.8(0.8)$ & $7.5(0.7)$ & $21(1)$ & $96(8)$ \\
& - & - & $1.25 \%$ & $1.25 \%$ \\
\hline
\end{tabular}

Table 3. Mean diffusion coefficients and weight gains at saturation

\begin{tabular}{|l|c|c|}
\hline & ILSS as-received, MPa & ILSS saturated with seawater, MPa \\
\hline Basalt/epoxy & $\mathbf{4 4 . 1}(1.7)$ & $\mathbf{3 4 . 3}(0.7)$ \\
\hline Glass/epoxy & $\mathbf{4 8 . 0}(1.6)$ & $\mathbf{3 8 . 7}(0.7)$ \\
\hline
\end{tabular}

Table 4. ILSS results, mean (standard deviation) before and after aging 


\begin{tabular}{|l|c|c|c|c|}
\hline Material & $\begin{array}{c}\text { Modulus } E_{\mathrm{f}} \\
\text { initial, GPa }\end{array}$ & $\begin{array}{c}\text { Modulus } \mathrm{E}_{\mathrm{f}} \text { after } \\
\text { aging, } \mathrm{GPa}\end{array}$ & $\begin{array}{c}\text { Initial Strength, } \\
\sigma_{\mathrm{f}}, \mathrm{MPa}\end{array}$ & $\begin{array}{c}\text { Aged Strength, } \\
\sigma_{\mathrm{f}}, \mathrm{MPa}\end{array}$ \\
\hline Basalt/epoxy & $\mathbf{3 8 . 4 2}(0.41)$ & $\mathbf{3 6 . 4 9}(0.80)$ & $\mathbf{6 9 8}(18)$ & $\mathbf{5 2 6}(47)$ \\
\hline Glass/epoxy & $\mathbf{3 7 . 9 8}(0.95)$ & $\mathbf{3 6 . 4 3}(1.71)$ & $\mathbf{5 9 4}(30)$ & $\mathbf{5 5 9}(35)$ \\
\hline
\end{tabular}

Table 5. Flexural properties, mean (standard deviation) before and after aging

\begin{tabular}{|c|c|c|}
\hline Material & $\begin{array}{c}\text { Slope "B", Unaged } \\
\text { tested in SW } \\
\% / \text { decade }\end{array}$ & Reference \\
\hline UD Basalt/epoxy1 & -10.7 & Present work \\
\hline UD E Glass/epoxy1 & -12.4 & Present work \\
\hline UD E Glass/epoxy2 & -13.0 & {$[21]$} \\
\hline UD Advantex ${ }^{\mathrm{TM}}$ Glass/epoxy2 & -9.2 & {$[21]$} \\
\hline UD Carbon/epoxy3 & -6.1 & {$[22]$} \\
\hline
\end{tabular}

Table 6. Comparison with data from 4-point flexural fatigue tests on same test fixture performed in seawater 

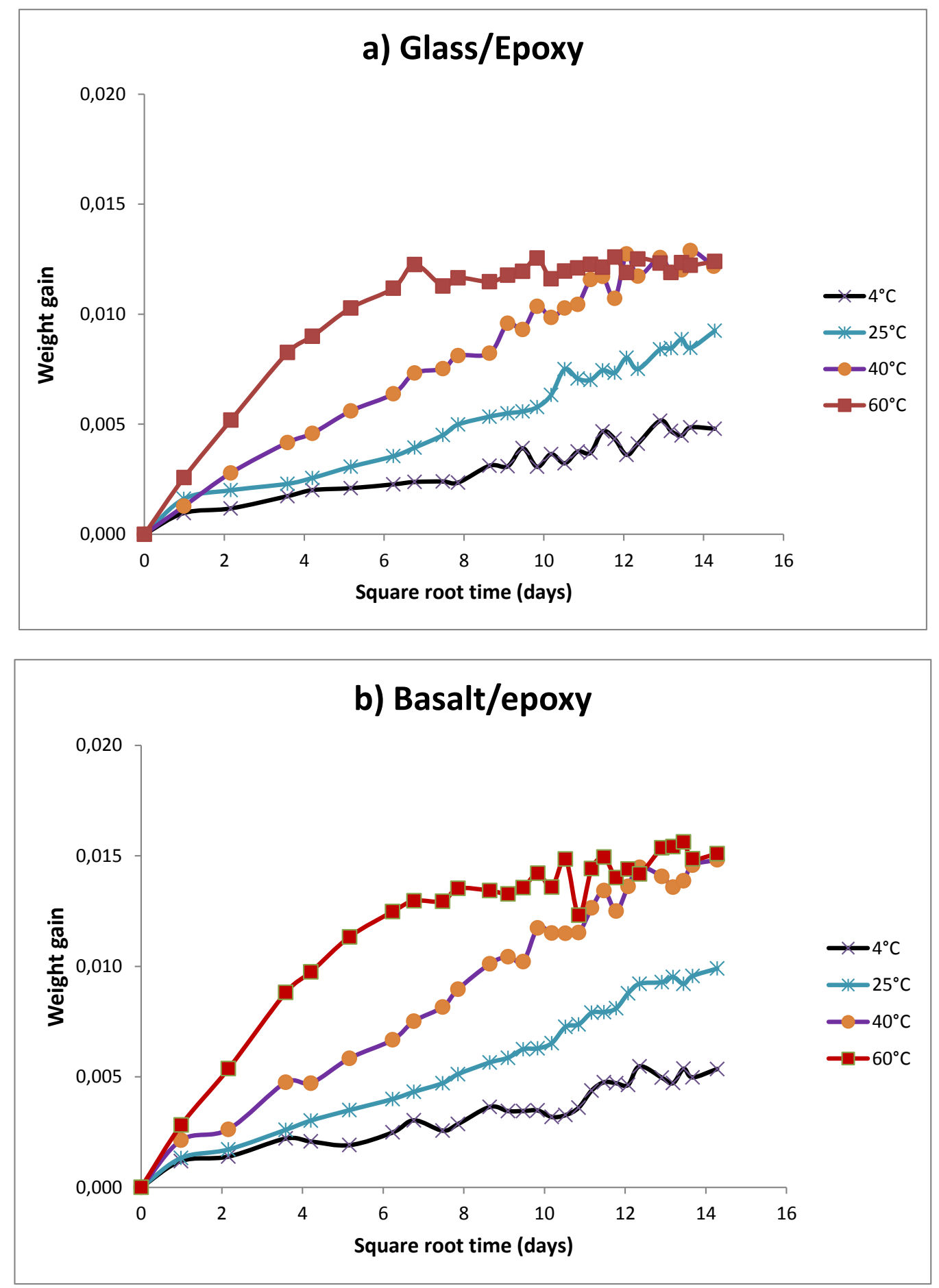

Figure 1. Examples of weight gain plots for 200 days' immersion at different temperatures,

a) Glass/epoxy, b) Basalt/epoxy 


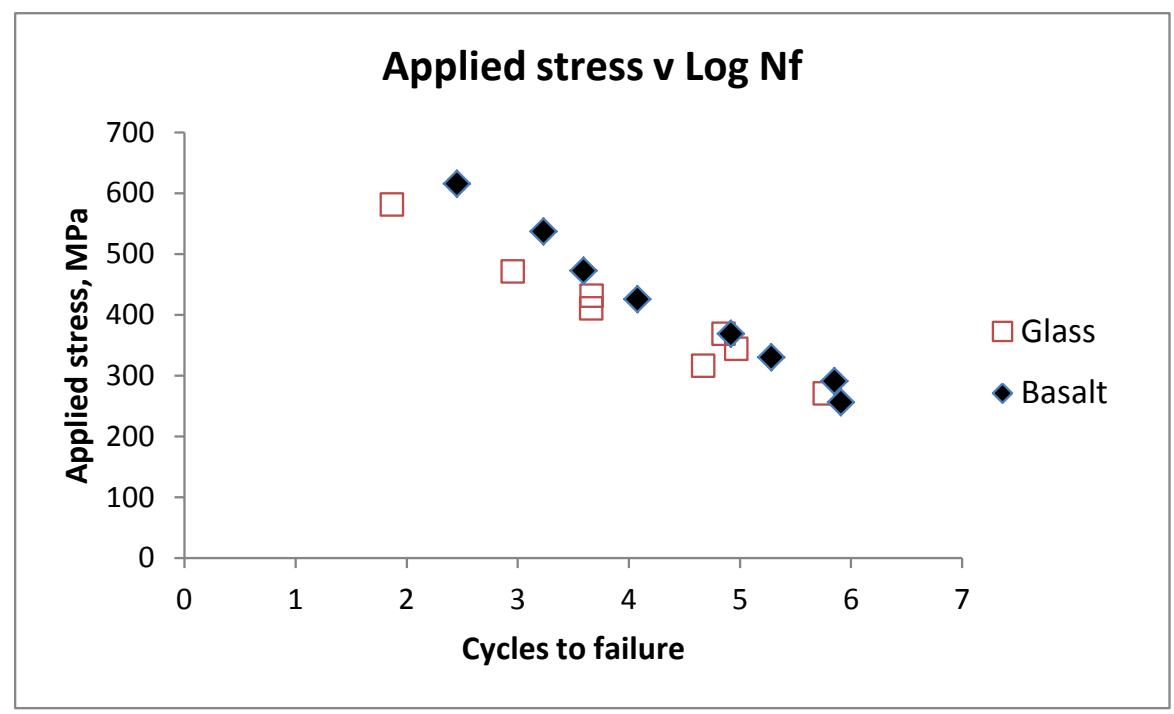

Figure 2. S-N plots unaged materials

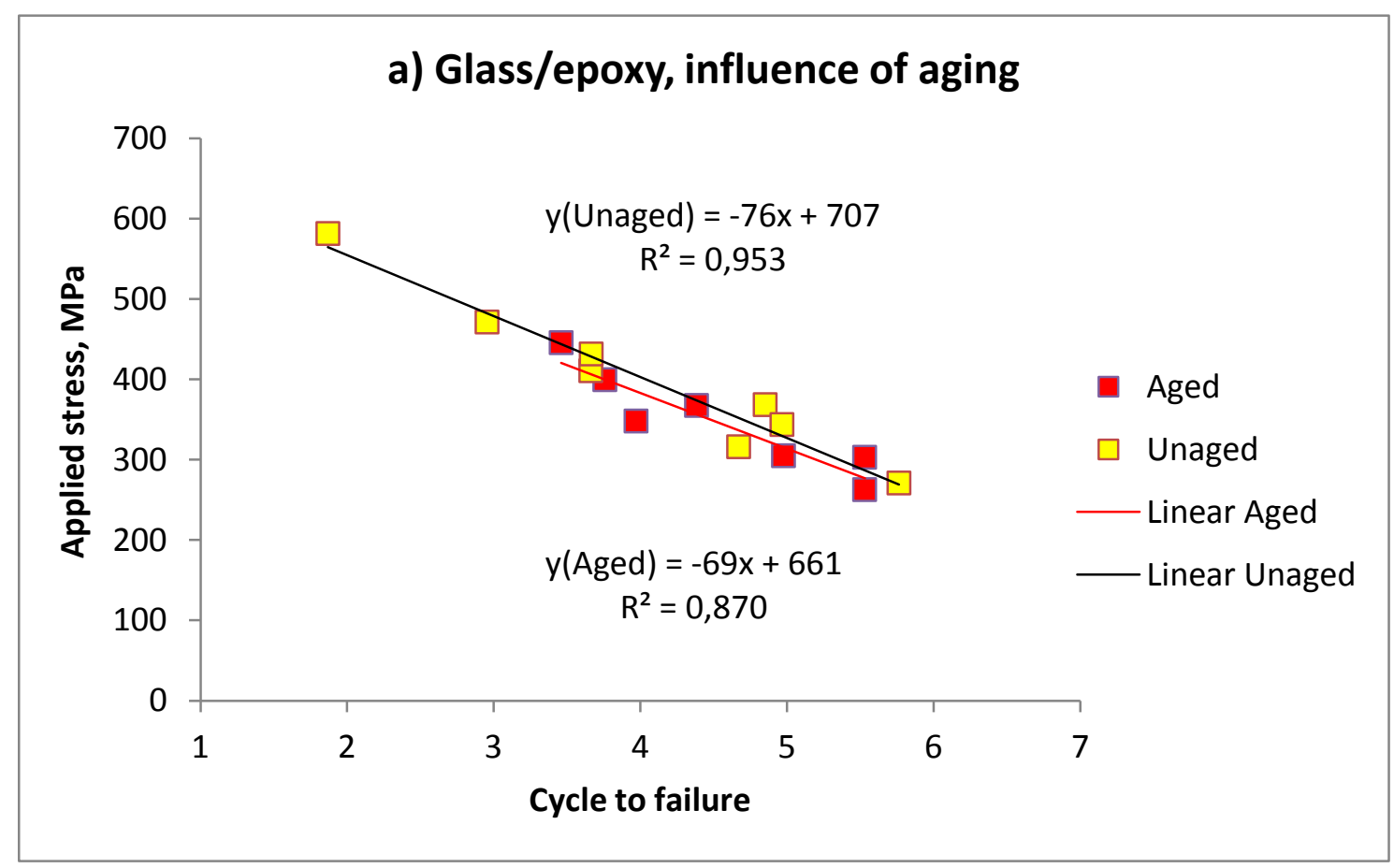




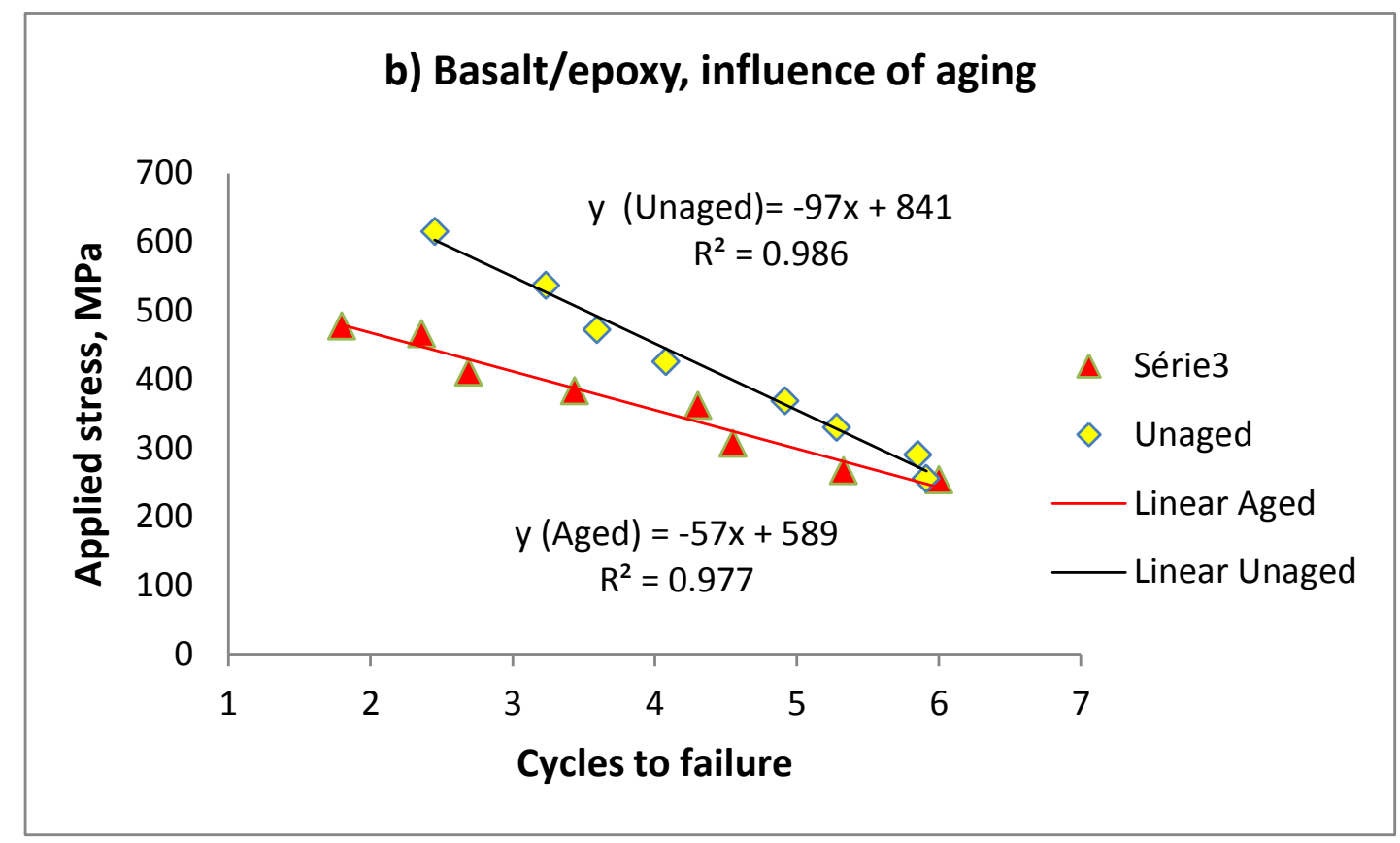

Figure 3. S-N plots for unaged and aged materials, a) Glass/epoxy, b) Basalt/epoxy

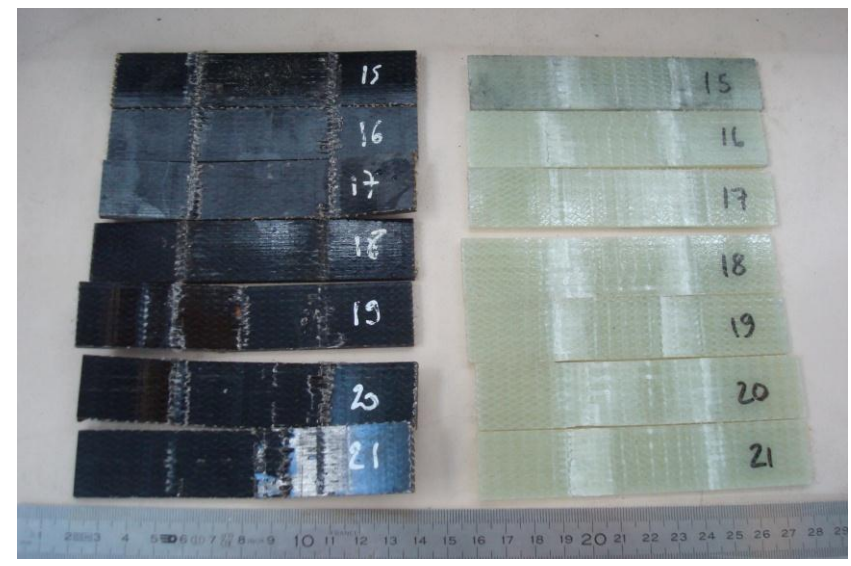

Figure 4. Flexural fatigue specimens showing failures on upper (compression) side of specimens, basalt/epoxy on left, glass/epoxy on right. 

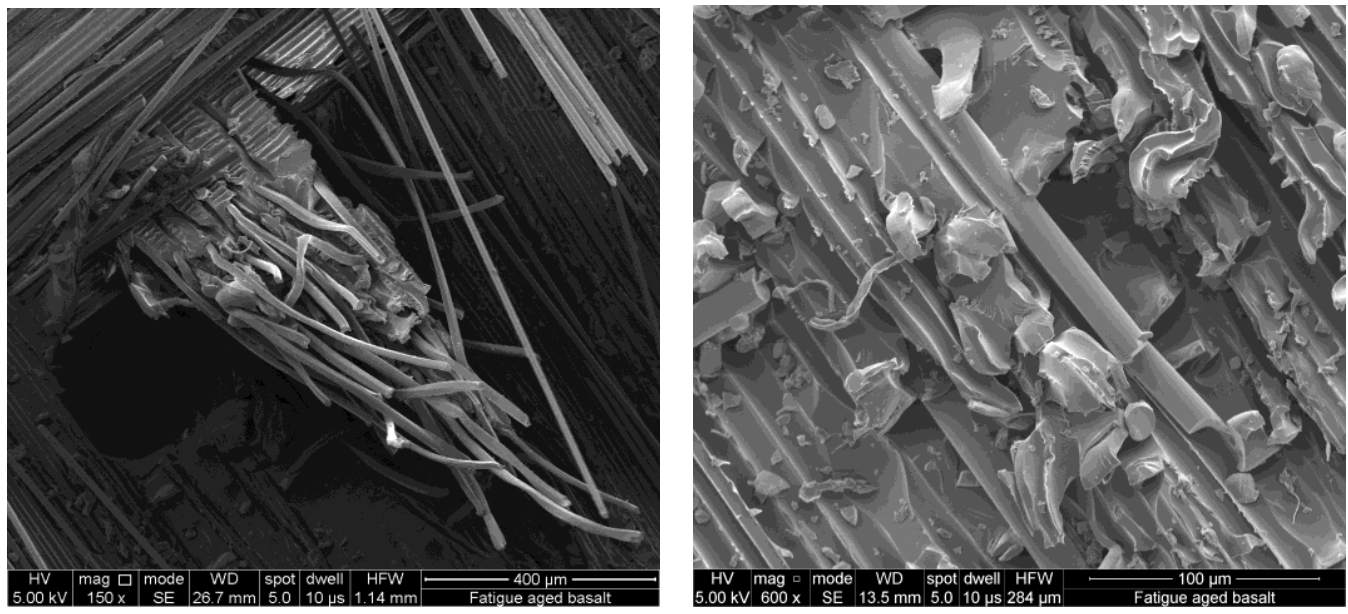

Figure 5. Fracture surfaces of aged basalt/epoxy composite after fatigue failure.

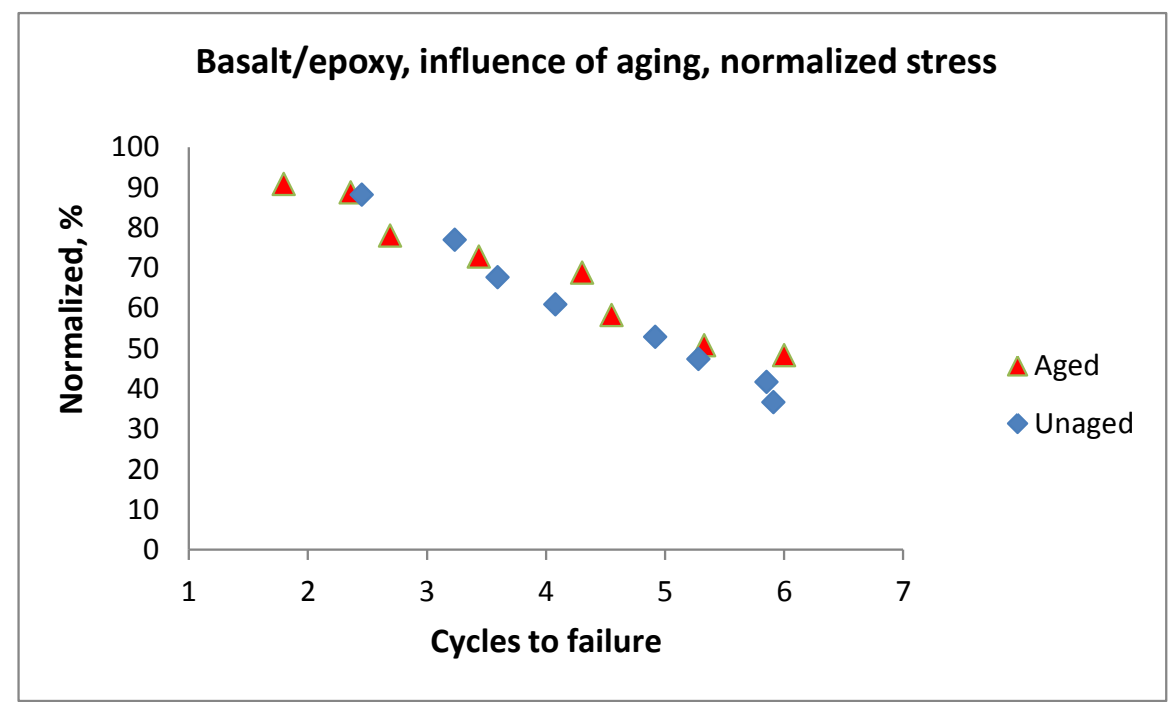

Figure 6. Normalized fatigue plots for basalt/epoxy. 


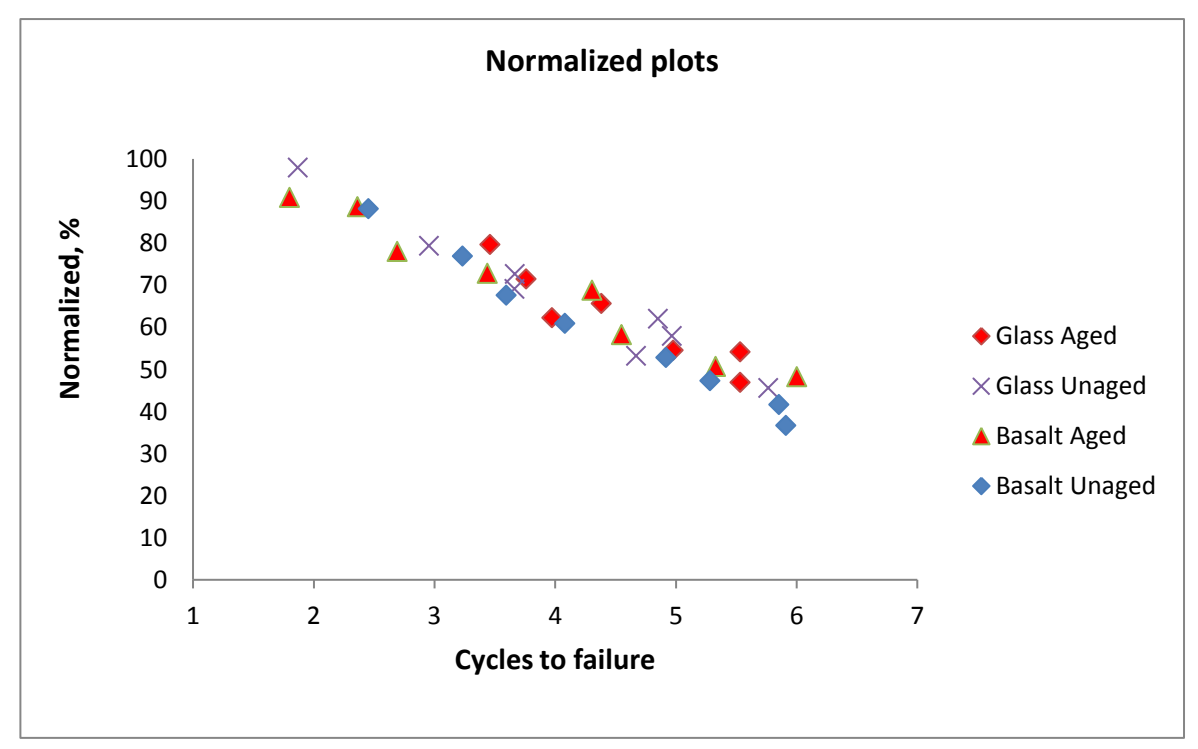

Figure 7. All fatigue data, before and after aging, normalized by quasi-static flexural strength values. 